\title{
Reduced Sympathetic Response to Head-Up Tilt in Subjects with Mild Cognitive Impairment or Mild Alzheimer's Dementia
}

\author{
Marte Rognstad Mellingsæter ${ }^{a, b} \quad$ Torgeir Bruun Wyller ${ }^{a, b}$ \\ Anette Hylen Ranhoffc, d Nenad Bogdanovica, b Vegard Bruun Wyllerb, e \\ a Department of Geriatric Medicine, Oslo University Hospital, b Institute of Clinical Medicine, \\ University of Oslo, and ' Diakonhjemmet Hospital, Oslo, ${ }^{\mathrm{d}}$ Department of Clinical Science, \\ University of Bergen, Bergen, and e Department of Pediatrics, Akershus University Hospital, \\ Lørenskog, Norway
}

Key Words

Autonomic function · Head-up tilt · Mild cognitive impairment · Alzheimer's dementia

\begin{abstract}
Background: Hemodynamic control was compared in patients with mild cognitive impairment (MCI) or mild Alzheimer's dementia (AD) as well as in healthy elderly subjects. Methods: Noninvasive, continuous hemodynamic recordings were obtained from 14 patients and 48 controls during supine rest (tilt of 30 and $70^{\circ}$ ). Cardiac output, end-diastolic volume, total peripheral resistance, heart rate variability (HRV), systolic blood pressure variability (SBPV), and baroreceptor sensitivity were calculated. Results: At $70^{\circ}$ tilt, the HRV indices differed significantly, with higher high-frequency (HF) variability as well as lower low-frequency (LF) variability and LF/HF ratios in the patients. The patients had significantly lower SBPV in the LF range at $30^{\circ}$ tilt. Conclusions: The results indicate a poorer sympathetic response to orthostatic stress in MCI and mild AD.

(C) 2015 S. Karger AG, Basel
\end{abstract}

\section{Introduction}

Ageing and falls are linked, and people with dementia are especially prone to falls $[1,2]$. Falls are complex, with multifactorial etiology [3]. Falls, syncope, orthostatic hypotension, and dizziness are features of neurocardiovascular instability, which is overrepresented in dementia, above all in dementia with Lewy bodies and Parkinson's disease dementia [4]. However, also patients with Alzheimer's dementia (AD) and mild cognitive impairment (MCI) have been shown to have increased orthostatic hypotension [5-7]. The mechanisms are still unclear. 
Mellingsæter et al.: Reduced Sympathetic Response to Head-Up Tilt in Subjects with Mild Cognitive Impairment or Mild Alzheimer's Dementia

Normal ageing is associated with a continuous reduction in heart rate variability (HRV), and gender differences diminish with age $[8,9]$. While young people rely more on vagal withdrawal [augmented heart rate (HR)] to maintain blood pressure in situations with orthostatic challenge, elderly people rely more on an increase in total peripheral resistance (vascular sympathetic constriction) [10]. In patients with $\mathrm{AD}$, both unchanged $[5,11]$ and decreased $[6$, $12,13]$ autonomic function at rest has been reported. An interpretation can be difficult due to comorbidity and extensive use of cardiovascular medication.

The aim of this study was to assess differences in autonomic cardiovascular control between patients with MCI or mild AD and healthy controls. All participants were free from cardiovascular disease and cardiovascular medication.

\section{Subjects and Methods}

\section{Subjects}

Fourteen patients diagnosed with MCI or AD of mild severity [defined as a Mini-Mental State Examination (MMSE) [14] score $>20$ and a Clinical Dementia Rating (CDR) [15] of 0.5-1] were recruited from the Memory Clinic at the Oslo University Hospital. The Memory Clinic is a highly specialized outpatient clinic, and all patients had undergone a thorough diagnostic workup, including several cognitive tests and CT scanning of the brain with measures of hippocampal atrophy. Forty-eight healthy controls were recruited from senior walking groups, senior centers, and golf clubs as well as from participants in healthy ageing courses.

All participants were $\geq 65$ years old, and none of them were daily smokers. The healthy controls had no chronic diseases, nor were they regularly using any drugs, except for vitamins, cod-liver oil, or acetylsalicylic acid. All healthy controls had normal cognitive function and completed the full test protocol including a head-up tilt test (HUT) for $40 \mathrm{~min}$. Participants with MCI or mild AD were selected from the register at the memory clinic. None had cardiovascular disease or used antihypertensive medication. Standard blood tests for screening were performed to confirm the absence of any biochemically detectable illnesses such as anemia, liver disorders, kidney failure, or heart failure. BMI was calculated from assessments of height and weight. Weight was measured while standing on an electronic scale with light clothes, and height while standing against a wall-attached measure.

\section{Head-Up Tilt Test}

The participants were asked not to drink beverages containing alcohol or caffeine from 8 p.m. on the day before the assessment. They were told to eat a light breakfast, and to drink 1 , but not more than 2, glasses (e.g. water, milk, juice) on the day of assessment. The same investigator (M.R.M.) performed all the assessments in a quiet room maintained at a comfortable temperature. The subjects lay supine on a tilt table with footboard support. A 5 -min baseline recording was obtained before the subjects were tilted head up to $30^{\circ}$ for 10 min. They were then tilted back to a horizontal position for $10 \mathrm{~min}$ before they again were tilted head up to $70^{\circ}$ over approximately $18 \mathrm{~s}$. The controls remained in tilted position for 40 min or until syncope or unbearable orthostatic intolerance occurred. The patients were tilted to $70^{\circ}$ for 6-8 min only. This difference is without implications for the results, since the epochs used for calculations are limited to the first $5 \mathrm{~min}$ after head-up tilt. The chosen tilt angle and time in head-up tilt position is in line with the Newcastle protocols from 2008 [16]. The subjects were asked not to speak except for comments about symptoms or to mention discomfort. 
Mellingsæter et al.: Reduced Sympathetic Response to Head-Up Tilt in Subjects with Mild Cognitive Impairment or Mild Alzheimer's Dementia

\section{Recordings}

During the HUT, the subjects were connected to the Task Force ${ }^{\circledR}$ Monitor (Model 3040i; CNSystems Medizintechnik, Graz, Austria), a combined hardware and software device for the noninvasive recording of cardiovascular variables [17]. Heart rate and R-R interval (RRI) were obtained from the ECG. Impedance cardiography, a method in which a small electrical potential is applied between three band electrodes on the neck and upper abdomen, was used to obtain a continuous recording of the temporal derivate of the transthoracic impedance (dZ/dt) [18]. Using the vascular unloading technique [19], continuous blood pressure was recorded from the second or middle finger of the right hand and calibrated every second minute against the oscillometric measurement of arterial blood pressure in the left arm.

\section{Data Analysis}

All recorded signals were transferred on-line to the built-in recording computer of the Task Force ${ }^{\circledR}$ Monitor, which was running software for real-time data acquisition. Beat-tobeat stroke volume and end-diastolic volume index were calculated from the impedance signal [17]. Cardiac output was calculated from HR and stroke volume. Beat-to-beat stroke index and cardiac index were obtained by dividing stroke volume and cardiac output by body surface area, estimated from the subject's height and weight. The total peripheral resistance index was calculated from the mean arterial blood pressure divided by cardiac output and body surface area.

We selected epochs of 4 min length from each test person in the resting state and in the tilted positions of 30 and $70^{\circ}$. Both of the latter epochs started after an initial stabilization period of $30 \mathrm{~s}$ from initiation of tilt. Delta tilt values were calculated $\left(30^{\circ}\right.$ tilt - rest and $70^{\circ}$ tilt - rest). Ectopic beats and their corresponding blood pressure values were manually removed and replaced with linear interpolation; recordings with $>10 \%$ ectopic beats were excluded.

The Task Force ${ }^{\circledR}$ Monitor uses an autoregressive algorithm to compute spectral power densities from consecutive segments of the biosignals [20]. The default output is spectral power densities of RRI and blood pressures in the low-frequency (LF; 0.04- to $0.15-\mathrm{Hz}$ ) band and the high-frequency (HF; $0.15-$ to $0.4-\mathrm{Hz}$ ) band, both in absolute $\left(\mathrm{LF}_{\mathrm{abs}} / \mathrm{HF}_{\mathrm{abs}}\right)$ and normalized units $\left(\mathrm{LF}_{\mathrm{nu}} / \mathrm{HF}_{\mathrm{nu}}\right)$. An index of baroreceptor sensitivity (BRS) was obtained from the Task Force ${ }^{\circledR}$ Monitor, using the 'sequence method' from Lag0 registrations, i.e. changes in HR lasting a minimum of 3 consecutive beats following a change in blood pressure [21].

In accordance with the definition of orthostatic hypotension [22], orthostatic blood pressure was calculated as the difference $(\Delta)$ between the nadir in continuous blood pressure and the blood pressure at rest before head-up tilt. Nadir systolic blood pressure (SBP) and diastolic blood pressure (DBP) were defined as the lowest pressure within the first $3 \mathrm{~min}$ after full head-up tilt to $70^{\circ}$.

\section{Statistical Analysis}

The data were exported to Microsoft Excel ${ }^{\circledR}$ for further calculations and then transported to SPSS (SPSS Inc., Chicago, Ill., USA) for statistical analysis. We then computed the median of all the hemodynamic variables and BRS in all the epochs and calculated the means with standard deviation (SD) for the groups separately. For the variability data, medians and quartiles are reported. For the baroreceptor data, extreme outliers (4 recordings, 3 controls) were excluded. Data plots were inspected to assess distribution. For group comparisons, parametric ( $\mathrm{t}$ test) or nonparametric (Mann-Whitney test) were applied as appropriate. A p value of $\leq 0.05$ was considered statistically significant. 
Mellingsæter et al.: Reduced Sympathetic Response to Head-Up Tilt in Subjects with Mild Cognitive Impairment or Mild Alzheimer's Dementia

Table 1. Hemodynamic regulation at rest and during 30 and $70^{\circ} \mathrm{HUT}$, comparing patients with $\mathrm{MCI}$ or mild AD with healthy controls

\begin{tabular}{|c|c|c|c|c|c|c|c|c|c|c|}
\hline & \multicolumn{2}{|l|}{ Rest } & \multicolumn{2}{|l|}{$30^{\circ}$ tilt } & \multicolumn{2}{|c|}{ Change after $30^{\circ}$ tilt } & \multicolumn{2}{|l|}{$70^{\circ}$ tilt } & \multicolumn{2}{|c|}{ Change after $70^{\circ}$ tilt } \\
\hline & patients & controls & patients & controls & patients & controls & patients & controls & patients & controls \\
\hline HR, beats/min & $61(7)$ & $61(8)$ & $66(8)$ & $65(9)$ & $5(4)$ & $5(4)$ & $73(11)$ & $71(9)$ & $11(8)$ & $11(5)$ \\
\hline $\mathrm{SBP}, \mathrm{mm} \mathrm{Hg}$ & $125(10)$ & $123(16)$ & $115(15)$ & $120(16)$ & $-9(11)$ & $-3(8)$ & $120(18)$ & $119(16)$ & $-4(16)$ & $-4(14)$ \\
\hline $\mathrm{DBP}, \mathrm{mm} \mathrm{Hg}$ & $80(8)$ & $81(12)$ & $79(12)$ & $81(12)$ & $-2(9)$ & $0(6)$ & $83(13)$ & $80(11)$ & $3(11)$ & $0(10)$ \\
\hline $\mathrm{MAP}, \mathrm{mm} \mathrm{Hg}$ & $92(8)$ & $93(12)$ & $88(12)$ & $91(12)$ & $-5(11)$ & $-1(7)$ & $92(13)$ & $90(12)$ & $0(13)$ & $-2(11)$ \\
\hline $\mathrm{SI}, \mathrm{ml} / \mathrm{m}^{2}$ & $43(10)$ & $42(9)$ & $36(7)$ & $35(6)$ & $-7(6)$ & $-8(8)$ & $33(6)$ & $33(4)$ & $-9(7)$ & $-10(9)$ \\
\hline $\mathrm{CI}, \mathrm{l} / \mathrm{min} / \mathrm{m}^{2}$ & $2.6(0.6)$ & $2.6(0.6)$ & $2.4(0.5)$ & $2.2(0.4)$ & $-0.2(0.4)$ & $-0.3(0.4)$ & $2.4(0.4)$ & $2.3(0.3)$ & $-0.2(0.5)$ & $-0.2(0.5)$ \\
\hline TPRI, $\mathrm{mm} \mathrm{Hg} / \mathrm{l} / \mathrm{min} / \mathrm{m}^{2}$ & $11.4(3.5)$ & $11.6(3.1)$ & $11.8(3.9)$ & $12.7(2.9)$ & $0.4(2.8)$ & $1.1(2.3)$ & $12.0(3.2)$ & $12.2(2.7)$ & $0.7(2.9)$ & $0.4(2.8)$ \\
\hline EDI, $\mathrm{ml} / \mathrm{m}^{2}$ & $70(15)$ & $70(15)$ & $62(12)$ & $59(9)$ & $-7(9)$ & $-11(11)$ & $59(10)$ & $58(7)$ & $-11(11)$ & $-12(13)$ \\
\hline
\end{tabular}

Values are means (SD) for the medians obtained from registration during sequences of 4 min at rest and tilt to 30 and $70^{\circ}$, and changes from rest after tilt to 30 and $70^{\circ}$. MAP = Mean blood pressure; SI = stroke index; CI = cardiac index; TPRI = total peripheral resistance index (indexed values are stroke volume; cardiac output and total peripheral resistance divided by body surface area); EDI = end-diastolic volume index.

\section{Ethics}

Written, informed consent was obtained from all participants. The patients with MCI or mild AD were assessed with a shorter protocol than the controls. All were considered competent of giving consent. Because of the likelihood that cognitive capacity could influence the understanding of the project, stamina, or the reporting of symptoms, the patients were not exposed to the entire protocol. All participants were informed about the risk of dizziness or syncope during the HUT and were secured with safety belts and asked to report symptoms of discomfort during the test. The study complied with the Declaration of Helsinki and was approved by the Regional Committee for Ethics in Medical Research.

\section{Results}

Fourteen patients ( 7 women) with MCI or mild AD, i.e. with a mean MMSE score of 24.8 (SD 2.4) and a median CDR of 1 (range 0.5-2), as well as 48 healthy controls ( 24 women) were included. Their mean age did not differ significantly: 73.6 years (SD 5.7) for the patients and 72.0 years (SD 6.0) for the controls. Their BMI was identical, with a mean value in both groups of 23.5 (SD 2.8, also identical).

We were unable to recruit participants with $\mathrm{MCI}$ or mild $\mathrm{AD}$ who did not use any medication. Five patients used acetyl cholinesterase inhibitors (ChEIs), 4 used levothyroxine, and 5 used psychotropic drugs, mainly selective serotonin reuptake inhibitors (SSRIs).

\section{Standard Hemodynamic Variables}

The blood pressures, HRs, stroke indices, cardiac indices, total peripheral resistance indices, and end-diastolic volume indices were similar across the two groups (table 1).

\section{Orthostasis}

The mean change in orthostatic blood pressures ( $\Delta$ values) was significant according to the consensus definition (decrease of $>20 / 10 \mathrm{~mm} \mathrm{Hg}$ in SBP/DBP within $3 \mathrm{~min}$ after standing) in both groups, but it did not differ between the groups. The $\triangle \mathrm{SBP}$ values were $24 \mathrm{~mm} \mathrm{Hg}$ (SD 19) and $25 \mathrm{~mm} \mathrm{Hg}$ (SD 17), and the $\triangle \mathrm{DBP}$ values were $11 \mathrm{~mm} \mathrm{Hg}$ (SD 12) and $14 \mathrm{~mm} \mathrm{Hg}$ (SD 12 ), in the patient and control groups, respectively. 
Table 2. HRV (frequency domain measures) and BRS at rest and during 30 and $70^{\circ} \mathrm{HUT}$, comparing patients with MCI or mild AD with healthy controls

\begin{tabular}{|c|c|c|c|c|c|c|c|c|c|c|}
\hline & \multicolumn{2}{|l|}{ Rest } & \multicolumn{2}{|l|}{$30^{\circ}$ tilt } & \multicolumn{2}{|c|}{ Change after $30^{\circ}$ tilt } & \multicolumn{2}{|l|}{$70^{\circ}$ tilt } & \multicolumn{2}{|c|}{ Change after $70^{\circ}$ tilt } \\
\hline & patients & controls & patients & controls & patients & controls & patients & controls & patients & controls \\
\hline $\mathrm{LF}_{\mathrm{nu}} \mathrm{RRI}$ & $\begin{array}{l}51 \\
(39-68)\end{array}$ & $\begin{array}{l}61 \\
(48-73)\end{array}$ & $\begin{array}{l}52 \\
(32-69)\end{array}$ & $\begin{array}{l}62 \\
(46-75)\end{array}$ & $\begin{array}{l}1 \\
(-21 \text { to } 16)\end{array}$ & $\begin{array}{l}0 \\
(-5 \text { to } 7)\end{array}$ & $\begin{array}{l}59^{* *} \\
(44-64)\end{array}$ & $\begin{array}{l}69 \\
(56-80)\end{array}$ & $\begin{array}{l}-4 \\
(-13 \text { to } 20)\end{array}$ & $\begin{array}{l}7 \\
\text { (-4 to } 15)\end{array}$ \\
\hline $\mathrm{HF}_{\mathrm{nu}} \mathrm{RRI}$ & $\begin{array}{l}49 \\
(32-61)\end{array}$ & $\begin{array}{l}39 \\
(27-52)\end{array}$ & $\begin{array}{l}48 \\
(31-68)\end{array}$ & $\begin{array}{l}38 \\
(25-54)\end{array}$ & $\begin{array}{l}-1 \\
(-16 \text { to } 21)\end{array}$ & $\begin{array}{l}0 \\
(-7 \text { to } 5)\end{array}$ & $\begin{array}{l}42^{* *} \\
(36-56)\end{array}$ & $\begin{array}{l}31 \\
(20-44)\end{array}$ & $\begin{array}{l}4 \\
(-20 \text { to } 13)\end{array}$ & $\begin{array}{l}-7 \\
(-15 \text { to } 4)\end{array}$ \\
\hline $\mathrm{LF}_{\mathrm{abs}} \mathrm{RRI}, \mathrm{ms}^{2}$ & $\begin{array}{l}303 \\
(69-502)\end{array}$ & $\begin{array}{l}289 \\
(142-903)\end{array}$ & $\begin{array}{l}187 \\
(48-782)\end{array}$ & $\begin{array}{l}233 \\
(120-429)\end{array}$ & $\begin{array}{l}-43 \\
(-153 \text { to } 59)\end{array}$ & $\begin{array}{l}-37 \\
(-207 \text { to } 64)\end{array}$ & $\begin{array}{l}133 \\
(58-405)\end{array}$ & $\begin{array}{l}247 \\
(122-534)\end{array}$ & $\begin{array}{l}-56 \\
(-230 \text { to } 44)\end{array}$ & $\begin{array}{l}-42 \\
(-263 \text { to } 61)\end{array}$ \\
\hline $\mathrm{HF}_{\mathrm{abs}} \mathrm{RRI}, \mathrm{ms}^{2}$ & $\begin{array}{l}209 \\
(68-489)\end{array}$ & $\begin{array}{l}212 \\
(73-928)\end{array}$ & $\begin{array}{l}413 \\
(31-822)\end{array}$ & $\begin{array}{l}147 \\
(56-616)\end{array}$ & $\begin{array}{l}-11 \\
(-105 \text { to } 294)\end{array}$ & $\begin{array}{l}-29 \\
(-269 \text { to } 25)\end{array}$ & $\begin{array}{l}170 \\
(46-584)\end{array}$ & $\begin{array}{l}120 \\
(37-360)\end{array}$ & $\begin{array}{l}-36 \\
(-266 \text { to } 38)\end{array}$ & $\begin{array}{l}-43 \\
(-371 \text { to } 40)\end{array}$ \\
\hline $\mathrm{LF} / \mathrm{HF}$ ratio & $\begin{array}{l}1.1 \\
(0.7-2.3)\end{array}$ & $\begin{array}{l}1.5 \\
(0.9-2.6)\end{array}$ & $\begin{array}{l}1.1 \\
(0.5-2.0)\end{array}$ & $\begin{array}{l}1.7 \\
(0.8-3.0)\end{array}$ & $\begin{array}{l}0.3 \\
(0.1-3.0)\end{array}$ & $\begin{array}{l}1.0 \\
(0.2-2.3)\end{array}$ & $\begin{array}{l}1.2^{* *} \\
(0.8-2.2)\end{array}$ & $\begin{array}{l}2.1 \\
(1.3-4.1)\end{array}$ & $\begin{array}{l}0.8 \\
(0-1.4)\end{array}$ & $\begin{array}{l}1.1 \\
(0.1-2.9)\end{array}$ \\
\hline $\mathrm{BRS}^{\mathrm{a}}, \mathrm{ms} / \mathrm{mm} \mathrm{Hg}$ & $8(6)$ & $10(7)$ & $7(9)$ & $8(5)$ & $-2(4)$ & $-2(7)$ & $6(4)$ & $6(4)$ & $-2(4)$ & $-3(7)$ \\
\hline
\end{tabular}

Values are medians (1st and 3rd quartiles) obtained from registration during sequences of 4 min at rest, and after tilt to 30 and $70^{\circ}$, respectively. Change after 30 and $70^{\circ}$ tilt is compared to resting values. $\mathrm{LF}_{\mathrm{nu}} \mathrm{RRI}$ and $\mathrm{HF}_{\mathrm{nu}} \mathrm{RRI}=\mathrm{LF}$ and HF power in normalized units [i.e. $\mathrm{LF}$ or $\mathrm{HF} /($ total power - very low frequency $\times 100$ )]; $\mathrm{LF}_{\mathrm{abs}} \mathrm{RRI}$ and $\mathrm{HF}_{\mathrm{abs}} \mathrm{RRI}=$ power in the LF and HF ranges in absolute values. ${ }^{* *} \mathrm{p} \leq 0.05$ compared with controls.

${ }^{a}$ Values are means (SD) for the medians obtained from Lag0 registrations by the sequence method from the same 4-min sequences as above.

Table 3. Blood pressure variability (frequency domain measures) at rest and during 30 and $70^{\circ} \mathrm{HUT}$, comparing patients with MCI or mild AD with healthy controls

\begin{tabular}{|c|c|c|c|c|c|c|c|c|c|c|}
\hline & \multicolumn{2}{|l|}{ Rest } & \multicolumn{2}{|l|}{$30^{\circ}$ tilt } & \multicolumn{2}{|c|}{ Change after $30^{\circ}$ tilt } & \multicolumn{2}{|l|}{$70^{\circ}$ tilt } & \multicolumn{2}{|c|}{ Change after $70^{\circ}$ tilt } \\
\hline & patients & controls & patients & controls & patients & controls & patients & controls & patients & controls \\
\hline $\mathrm{LF}_{\mathrm{nu}} \mathrm{SBP}$ & $\begin{array}{l}38 \\
(26-47)\end{array}$ & $\begin{array}{l}39 \\
(35-47)\end{array}$ & $\begin{array}{l}30^{* *} \\
(26-44)\end{array}$ & $\begin{array}{l}42 \\
(37-48)\end{array}$ & $\begin{array}{l}-2.4^{* *} \\
(-7.6 \text { to } 1.1)\end{array}$ & $\begin{array}{l}1.4 \\
(-1.9 \text { to } 4.9)\end{array}$ & $\begin{array}{l}34 \\
(29-49)\end{array}$ & $\begin{array}{l}45 \\
(37-54)\end{array}$ & $\begin{array}{l}-2.1 \\
(-7.1 \text { to } 1.8)\end{array}$ & $\begin{array}{l}5.4 \\
(-5.3 \text { to } 10)\end{array}$ \\
\hline $\mathrm{LF}_{\mathrm{abs}} \mathrm{SBP}, \mathrm{mm} \mathrm{Hg}{ }^{2}$ & $\begin{array}{l}8 \\
(6-15)\end{array}$ & $\begin{array}{l}6 \\
(4-10)\end{array}$ & $\begin{array}{l}7 \\
(4-11)\end{array}$ & $\begin{array}{l}6 \\
(4-9)\end{array}$ & $\begin{array}{l}-2.2^{*} \\
(-4.0 \text { to }-1.2)\end{array}$ & $\begin{array}{l}-0.7 \\
(-1.4 \text { to }-0.3)\end{array}$ & $\begin{array}{l}5 \\
(3-8)\end{array}$ & $\begin{array}{l}4 \\
(3-7)\end{array}$ & $\begin{array}{l}-3.2 \\
(-8.2 \text { to }-1.0)\end{array}$ & $\begin{array}{l}-1.9 \\
(-4.3 \text { to }-0.8)\end{array}$ \\
\hline $\mathrm{LF} / \mathrm{HF}$ & $\begin{array}{l}3.9 \\
(3.2-6.7)\end{array}$ & $\begin{array}{l}4.2 \\
(3.0-5.5)\end{array}$ & $\begin{array}{l}3.4 \\
(2.7-5.3)\end{array}$ & $\begin{array}{l}4.2 \\
(3.2-5.7)\end{array}$ & $\begin{array}{l}-0.9^{*} \\
(-1.5 \text { to } 0)\end{array}$ & $\begin{array}{l}-0 \\
(-0.4 \text { to } 0.4)\end{array}$ & $\begin{array}{l}2.9 \\
(2.0-4.6)\end{array}$ & $\begin{array}{l}3.9 \\
(2.7-6.1)\end{array}$ & $\begin{array}{l}-2.0^{* *} \\
(-3.8 \text { to } 0.1)\end{array}$ & $\begin{array}{l}-0.6 \\
(-1.6 \text { to } 0 .)\end{array}$ \\
\hline
\end{tabular}

Values are medians (1st and 3rd quartiles) obtained from registration during sequences of 4 min at rest, and after tilt to 30 and $70^{\circ}$, respectively. Change after 30 and $70^{\circ}$ tilt is compared with resting values. $L_{n u} S B P=L F$ power in normalized units [i.e. $L F /($ total power - very low frequency $\times 100)$ ]; $L F_{a b s} S B P=$ power in LF range in absolute values. ${ }^{*} \mathrm{p} \leq 0.01,{ }^{* *} \mathrm{p} \leq 0.05$ compared with controls.

\section{Autonomic Response to Mild Orthostatic Challenge ( $\left.30^{\circ} \mathrm{HUT}\right)$}

There were no significant differences in HRV responses at rest or after exposure to lowgrade tilt between the two groups; however, there was a tendency towards lower LF/HF ratios $(p=0.08)$ in the patient group (table 2$)$. BRS was also similar. SBP variability (SBPV) was equal at rest. At $30^{\circ}$ tilt, the MCI/AD patients had a significantly lower SBPV ( $\mathrm{p} \leq 0.05$ ) in the LF range (normalized units) and also a significantly more pronounced decrease in LF variability from baseline (both normalized and absolute units, $\mathrm{p} \leq 0.05$ and $\mathrm{p} \leq 0.01$, respectively) than the healthy controls (table 3).

\section{Autonomic Response to Strong Orthostatic Challenge $\left(70^{\circ} \mathrm{HUT}\right)$}

Although there were no differences either in standard cardiovascular variables or BRS after ordinary tilt to $70^{\circ}$, there were small but significant differences in HRV indices: $\mathrm{HF}_{\mathrm{nu}}$ was higher ( $\mathrm{p} \leq 0.05$ ) and $\mathrm{LF}_{\mathrm{nu}}$ and LF/HF ratio were lower $(\mathrm{p} \leq 0.05)$ in patients compared with controls (table 2). The SBPV index $\mathrm{LF}_{\text {nu }}$ was lower among the patients also after tilt to $70^{\circ}$. The difference between the groups was borderline significant $(p=0.07)$, while the decrease in LF/HF ratio from the supine to the tilt position was significantly larger $(p \leq 0.05)$ in the patient group. 
Mellingsæter et al.: Reduced Sympathetic Response to Head-Up Tilt in Subjects with Mild Cognitive Impairment or Mild Alzheimer's Dementia

\section{Discussion}

The most important finding was divergent HRV and SBPV responses to orthostatic challenge among patients with MCI or mild $\mathrm{AD}$, indicating an attenuation of sympathetic cardiovascular control and possibly reflecting early neuropathological processes in the brain.

\section{HR Variability}

Our groups were similar in age, BMI, gender distribution, and the absence of cardiovascular disease. Neither groups used cardiovascular medication. The observed differences in $\mathrm{HRV}$, lower LF/HF ratio (an index of sympathovagal balance) and $\mathrm{LF}_{\mathrm{nu}} \mathrm{RRI}$ (power in the LF range) during both low-grade and full head-up tilt might be early signs of poorer sympathetic response among patients with $\mathrm{MCI}$ or mild $\mathrm{AD}$. This is supported by the observed decrease in $\mathrm{LF}_{\mathrm{abs}}$ among the patients (although not statistically significant) with increasing tilt angle, while $L_{a b s}$ remained unchanged in the controls. The decreased $L_{a b s}$ in turn influences the sympathetic-parasympathetic balance, as reflected in the differences found in LF/HF ratio. It seems that parasympathetic function remained unchanged, which was also supported by the preserved BRS.

\section{SBP Variability}

Blood pressures and HR fluctuate from beat to beat and hour to hour, as well as over days and months. The interpretation of and physiological basis for blood pressure variability (BPV) are contentious [23], but there is agreement that LF power (and the very-low-frequency components) involve the action of the sympathetic nervous system on the vasculature in the arterioles $[23,24]$. Patients with $\mathrm{MCI}$ and mild AD had significantly lower $\mathrm{LF}_{\mathrm{nu}}$ components after tilt to $30^{\circ}$, and borderline significantly $(\mathrm{p}=0.07)$ lower ones after tilt to $70^{\circ}$, but not lower absolute values. The decreases in LF indices of BPV from supine to tilt were also significantly or near significantly larger in the patient group. This suggests lower sympathetic control of the arterioles in early stages of dementia.

Both HRV and SBPV were similar at rest in the two groups. Other researchers have also reported normal autonomic function in the supine position in $\mathrm{AD}[11,25]$. However, decreased autonomic function, mainly parasympathetic dysfunction $[6,13]$ or both parasympathetic and sympathetic dysfunction [26], is more frequently reported. The degree of the dysfunction increases with the severity of the dementia [26]. In our study, differences in autonomic function became visible only after orthostatic challenge. This is in accordance with a recent study by Nicolini et al. [27], which showed evidence of autonomic dysfunction in MCI only in the upright position.

Autonomic dysfunction in dementia is often explained by a cholinergic deficiency $[25,26$, 28], and less emphasis has been put on decreases in sympathetic activity. An attenuated sympathetic response to head-up tilt might be a finding in the earliest stages of $A D$, possibly reflecting early neuropathological processes in the brain. Several brain regions are involved in the sympathetic regulation of blood pressure, in particular the reticular formation (including the rostral ventral lateral medulla, raphe nuclei, and locus caeruleus), the nucleus tractus solitarius, and hypothalamus [29]. Adrenaline-synthesizing neurons in the C1 region of the rostral ventral lateral medulla are reciprocally projected to the hypothalamus and might be regarded as a 'tonic' vasomotor center that regulates blood pressure via the baroreceptor reflex [30]. The same neurons also stimulate noradrenergic neurons in the locus caeruleus and have been termed the body's 'emergency medical technicians' due to their role in maintaining homeostasis [31]. These regions are affected by neurodegeneration and tangle formations in AD. Thirty percent of $\mathrm{C} 1$ neurons are lost in $\mathrm{AD}$ [32], and the locus caeruleus is probably the first site of identifiable tangle formation [33,34]. These findings might constitute 
a morphological substrate for the observation of decreased sympathetic cardiovascular control during orthostatic challenge.

Compared with young persons, elderly people rely on an increase in total peripheral resistance, i.e. vascular sympathetic regulation, rather than vagal withdrawal in situations of orthostatic challenge, which shows as a smaller decrease in HF and thus a smaller increase in LF/HF ratio [10]. Studies have also shown that ageing is associated with a smaller increase in LF power of BPV during orthostatic challenge [10,35]. In this aspect, our findings might indicate that changes related to ageing appear earlier in AD.

\section{Orthostatic Hypotension and Hemodynamic Function}

Contrary to what we expected, we did not find more orthostatic hypotension in patients with $\mathrm{MCI}$ or mild AD than in the control group. Nor did patients and controls differ in any of the other hemodynamic measures. This result is in conflict with that by Collins et al. [6], who found that an MCI group had a greater fall in orthostatic blood pressure than healthy controls. Their study differed from the present one in several respects: there were more participants, and the MCI group had more cardiovascular disease and a greater proportion of men, possibly influencing the results. Other studies have reported orthostatic hypotension in AD or MCI [5, 7], but these findings are frequently confounded by a more frequent use of antihypertensive drugs in their AD groups.

We used a tilt table where the upright position was reached in $18 \mathrm{~s}$. Other studies have used active stand, where the patients change from supine to standing within $3 \mathrm{~s}$. According to the consensus definition of orthostatic hypotension and measurements [22], active stand and the HUT are equal. We can, however, not exclude the possibility that our registration method yields a lower prevalence. New technology with continuous registrations of blood pressure has extended the possibilities for registering even the earliest changes [19]. RomeroOrtuno et al. [36] found that initial orthostatic hypotension [i.e. a decrease in blood pressure of $40 \mathrm{~mm} \mathrm{Hg}$ (systolic) or $20 \mathrm{~mm} \mathrm{Hg}$ (diastolic) within $15 \mathrm{~s}$ of standing] was related to falls and frailty, while orthostatic hypotension according to the consensus definition [22] was not.

\section{Strengths and Limitations}

The mean age was $>70$ years, both groups were without cardiovascular disease, and no one used antihypertensive drugs. These are considered important strengths of our design. The main limitation is the small patient group - and, ideally, all participants should have been free from all types of medication. Some of the patients used ChEIs and/or psychotropic drugs, mainly SSRIs. ChEIs can reduce HRV, but HF more than LF power [37]. In a recent study, patients were tested before and under treatment with ChEIs: the medication increased the LF/HF ratio and reduced HF power, but it did not influence the occurrence of orthostatic hypotension [38]. The use of ChEIs in our sample is therefore prone to diminish the differences rather than exaggerate them. SSRIs can cause orthostatic hypotension, but the patient group did not differ in any of the hemodynamic variables.

\section{Conclusion}

Orthostatic blood pressures and other hemodynamic variables did not differ between healthy controls and patients with MCI or mild AD without cardiovascular disease and antihypertensive treatment. The findings of decreased LF power and LF/HF ratio of HRV in the patient group during tilt, together with a larger decrease in LF power of BPV, suggest a poorer sympathetic response to orthostatic challenge in $\mathrm{AD}$. 
Mellingsæter et al.: Reduced Sympathetic Response to Head-Up Tilt in Subjects with Mild Cognitive Impairment or Mild Alzheimer's Dementia

\section{Acknowledgment}

This work was supported by the Oslo University Hospital.

\section{References}

1 Tinetti ME, Speechley M, Ginter SF: Risk factors for falls among elderly persons living in the community. N Engl J Med 1988;319:1701-1707.

-2 van Doorn C, Gruber-Baldini AL, Zimmerman S, Hebel JR, Port CL, Baumgarten M, Quinn CC, Taler G, May C, Magaziner J: Dementia as a risk factor for falls and fall injuries among nursing home residents. J Am Geriatr Soc 2003;51:1213-1218.

-3 Panel on Prevention of Falls in Older Persons, American Geriatrics Society and British Geriatrics Society: Summary of the updated American Geriatrics Society/British Geriatrics Society clinical practice guideline for prevention of falls in older persons. J Am Geriatr Soc 2011;59:148-157.

-4 Kenny RA, Kalaria R, Ballard C: Neurocardiovascular instability in cognitive impairment and dementia. Ann NY Acad Sci 2002;977:183-195.

5 Allan LM, Ballard CG, Allen J, Murray A, Davidson AW, McKeith IG, Kenny RA: Autonomic dysfunction in dementia. J Neurol Neurosurg Psychiatry 2007;78:671-677.

6 Collins O, Dillon S, Finucane C, Lawlor B, Kenny RA: Parasympathetic autonomic dysfunction is common in mild cognitive impairment. Neurobiol Aging 2012;33:2324-2333.

7 Mehrabian S, Duron E, Labouree F, Rollot F, Bune A, Traykov L, Hanon O: Relationship between orthostatic hypotension and cognitive impairment in the elderly. J Neurol Sci 2010;299:45-48.

-8 Barantke M, Krauss T, Ortak J, Lieb W, Reppel M, Burgdorf C, Pramstaller PP, Schunkert H, Bonnemeier H: Effects of gender and aging on differential autonomic responses to orthostatic maneuvers. J Cardiovasc Electrophysiol 2008;19:1296-1303.

-9 Felber Dietrich D, Schindler C, Schwartz J, Barthélémy JC, Tschopp JM, Roche F, von Eckardstein A, Brändli O, Leuenberger P, Gold DR, Gaspoz JM, Ackermann-Liebrich U: Heart rate variability in an ageing population and its association with lifestyle and cardiovascular risk factors: results of the SAPALDIA study. Europace 2006;8: 521-529.

10 Laitinen T, Niskanen L, Geelen G, Länsimies E, Hartikainen J: Age dependency of cardiovascular autonomic responses to head-up tilt in healthy subjects. J Appl Physiol (1985) 2004;96:2333-2340.

11 Allan LM, Kerr SR, Ballard CG, Allen J, Murray A, McLaren AT, Kenny RA: Autonomic function assessed by heart rate variability is normal in Alzheimer's disease and vascular dementia. Dement Geriatr Cogn Disord 2005; 19: 140-144.

12 Kim DH, Lipsitz LA, Ferrucci L, Varadhan R, Guralnik JM, Carlson MC, Fleisher LA, Fried LP, Chaves PH: Association between reduced heart rate variability and cognitive impairment in older disabled women in the community: Women's Health and Aging Study I. J Am Geriatr Soc 2006;54:1751-1757.

13 Toledo MA, Junqueira LF Jr: Cardiac autonomic modulation and cognitive status in Alzheimer's disease. Clin Auton Res 2010;20:11-17.

14 Folstein MF, Folstein SE, McHugh PR: 'Mini-mental state'. A practical method for grading the cognitive state of patients for the clinician. J Psychiatr Res 1975;12:189-198.

15 Hughes CP, Berg L, Danziger WL, Coben LA, Martin RL: A new clinical scale for the staging of dementia. Br J Psychiatry 1982;140:566-572.

16 Parry SW, Reeve P, Lawson J, Shaw FE, Davison J, Norton M, Frearson R, Kerr S, Newton JL: The Newcastle protocols 2008: an update on head-up tilt table testing and the management of vasovagal syncope and related disorders. Heart 2009;95:416-420.

-17 Fortin J, Habenbacher W, Heller A, Hacker A, Grüllenberger R, Innerhofer J, Passath H, Wagner C, Haitchi G, Flotzinger D, Pacher R, Wach P: Non-invasive beat-to-beat cardiac output monitoring by an improved method of transthoracic bioimpedance measurement. Comput Biol Med 2006;36:1185-1203.

18 Denniston JC, Maher JT, Reeves JT, Cruz JC, Cymerman A, Grover RF: Measurement of cardiac output by electrical impedance at rest and during exercise. J Appl Physiol 1976;40:91-95.

19 Imholz BP, Wieling W, van Montfrans GA, Wesseling KH: Fifteen years experience with finger arterial pressure monitoring: assessment of the technology. Cardiovasc Res 1998;38:605-616.

20 Heart rate variability: standards of measurement, physiological interpretation and clinical use. Task Force of the European Society of Cardiology and the North American Society of Pacing and Electrophysiology. Circulation 1996;93:1043-1065.

21 Bertinieri G, Di Rienzo M, Cavallazzi A, Ferrari AU, Pedotti A, Mancia G: A new approach to analysis of the arterial baroreflex. J Hypertens Suppl 1985;3:S79-S81.

-22 Consensus statement on the definition of orthostatic hypotension, pure autonomic failure, and multiple system atrophy. The Consensus Committee of the American Autonomic Society and the American Academy of Neurology. Neurology 1996;46:1470. 
23 Malpas SC: Neural influences on cardiovascular variability: possibilities and pitfalls. Am J Physiol Heart Circ Physiol 2002;282:H6-H20.

24 Laitinen T, Hartikainen J, Niskanen L, Geelen G, Länsimies E: Sympathovagal balance is major determinant of short-term blood pressure variability in healthy subjects. Am J Physiol 1999;276:H1245-H1252.

25 Giubilei F, Strano S, Imbimbo BP, Tisei P, Calcagnini G, Lino S, Frontoni M, Santini M, Fieschi C: Cardiac autonomic dysfunction in patients with Alzheimer disease: possible pathogenetic mechanisms. Alzheimer Dis Assoc Disord 1998;12:356-361.

26 Zulli R, Nicosia F, Borroni B, Agosti C, Prometti P, Donati P, De Vecchi M, Romanelli G, Grassi V, Padovani A: QT dispersion and heart rate variability abnormalities in Alzheimer's disease and in mild cognitive impairment. J Am Geriatr Soc 2005;53:2135-2139.

27 Nicolini P, Ciulla MM, Malfatto G, Abbate C, Mari D, Rossi PD, Pettenuzzo E, Magrini F, Consonni D, Lombardi F: Autonomic dysfunction in mild cognitive impairment: evidence from power spectral analysis of heart rate variability in a cross-sectional case-control study. PLoS One 2014; 9:e96656.

28 Bierer LM, Haroutunian V, Gabriel S, Knott PJ, Carlin LS, Purohit DP, Perl DP, Schmeidler J, Kanof P, Davis KL: Neurochemical correlates of dementia severity in Alzheimer's disease: relative importance of the cholinergic deficits. J Neurochem 1995;64:749-760.

29 Guyenet PG: The sympathetic control of blood pressure. Nat Rev Neurosci 2006; 7:335-346.

-30 Ross CA, Ruggiero DA, Park DH, Joh TH, Sved AF, Fernandez-Pardal J, Saavedra JM, Reis DJ: Tonic vasomotor control by the rostral ventrolateral medulla: effect of electrical or chemical stimulation of the area containing C1 adrenaline neurons on arterial pressure, heart rate, and plasma catecholamines and vasopressin. J Neurosci 1984;4:474-494.

31 Guyenet PG, Stornetta RL, Bochorishvili G, Depuy SD, Burke PG, Abbott SB: C1 neurons: the body's EMTs. Am J Physiol Regul Integr Comp Physiol 2013;305:R187-R204.

-32 Burke WJ, Coronado PG, Schmitt CA, Gillespie KM, Chung HD: Blood pressure regulation in Alzheimer's disease. J Auton Nerv Syst 1994;48:65-71.

-33 German DC, Manaye KF, White CL 3rd, Woodward DJ, McIntire DD, Smith WK, Kalaria RN, Mann DM: Diseasespecific patterns of locus coeruleus cell loss. Ann Neurol 1992;32:667-676.

-34 Chalermpalanupap T, Kinkead B, Hu WT, Kummer MP, Hammerschmidt T, Heneka MT, Weinshenker D, Levey AI: Targeting norepinephrine in mild cognitive impairment and Alzheimer's disease. Alzheimers Res Ther 2013;5:21.

-35 Barnett SR, Morin RJ, Kiely DK, Gagnon M, Azhar G, Knight EL, Nelson JC, Lipsitz LA: Effects of age and gender on autonomic control of blood pressure dynamics. Hypertension 1999;33:1195-1200.

-36 Romero-Ortuno R, Cogan L, Foran T, Kenny RA, Fan CW: Continuous noninvasive orthostatic blood pressure measurements and their relationship with orthostatic intolerance, falls, and frailty in older people. J Am Geriatr Soc 2011;59:655-665.

-37 Masuda Y, Kawamura A: Acetylcholinesterase inhibitor (donepezil hydrochloride) reduces heart rate variability. J Cardiovasc Pharmacol 2003;41(suppl 1):S67-S71.

-38 da Costa Dias FL, Ferreira Lisboa da Silva RM, de Moraes EN, Caramelli P: Cholinesterase inhibitors modulate autonomic function in patients with Alzheimer s disease and mixed dementia. Curr Alzheimer Res 2013;10: 476-481. 